Linköping Studies in Science and Technology

Dissertation No. 1826

\title{
Fluorinated SiC CVD
}

\section{Pontus Stenberg}

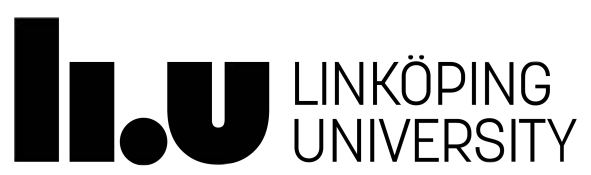

Division of Semiconductor materials

Department of Physics, Chemistry and Biology (IFM)

Linköping University, Sweden

Linköping 2017 
Front cover: $\mathrm{SiC}$ sample grown using $\mathrm{SiF}_{4}$ and $\mathrm{CH}_{4}$ as precursors. The sample was grown in the in the early exploration of the process window under the influence of technical issues. The growth is highly localized to an area of approximately $2 \mathrm{~mm} \times 7 \mathrm{~mm}$ shaped as a banana.

Back cover: $\mathrm{SiC}$ sample grown using $\mathrm{SiF}_{4}$ and $\mathrm{CH}_{4}$ as precursors when pushing the limits of the process window. The appearing ghost clearly indicates the dangers using fluorinated chemistry.

About the images: These images were taken by using an optical microscope equipped with a Nomarski prism and afterwards image manipulated to enhance the contrast of surface features. The colors are therefore not true colors. The samples are transparent and slightly greenish.

During the course of the research underlying this thesis, Pontus Stenberg was enrolled in Agora Materiae, a multidiciplinary doctoral program at Linköping University, Sweden.

(C) Copyright 2017 Pontus Stenberg, unless otherwise noted

Stenberg, Pontus

Fluorinated $\mathrm{SiC}$ CVD

ISBN: 978-91-7685-591-1

ISSN: 0345-7524

Linköping Studies in Science and Technology, Dissertation No. 1826

Electronic publication: http://www.ep.liu.se

Printed in Sweden by LiU-Tryck, Linköping 2017 
"The Guide is definitive.

Reality is frequently inaccurate."

- Douglas Adams,

The Hitchhiker's Guide to the Galaxy 



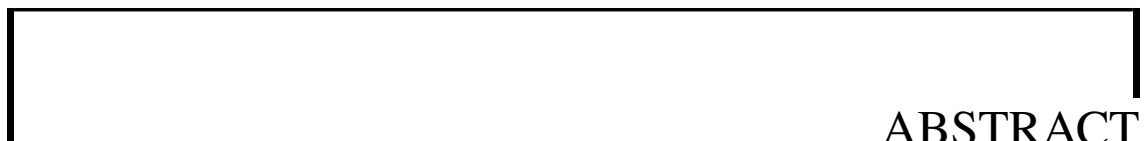

For the emerging semiconductor material silicon carbide (SiC) used in high power devices, chemical vapor deposition (CVD) is the most prominent method to create the electrically active $\mathrm{SiC}$ epitaxial layers in the device. The process of growing such epitaxial layers is to use a hydrocarbon and silane diluted in hydrogen flow through a hot chamber where chemical reactions take place in such a manner that $\mathrm{Si}$ and $\mathrm{C}$ finally deposit epitaxial $\mathrm{SiC}$. The addition of chlorine $(\mathrm{Cl})$ to the process has been thoroughly investigated due to its ability to reduce homogeneous nucleation in the gas phase attributed to the stronger $\mathrm{Si}-\mathrm{Cl}$ bond compared to the $\mathrm{Si}-\mathrm{Si}$ bond. In this thesis the fluorinated chemistry has been investigated, since the $\mathrm{Si}-\mathrm{F}$ bond is even stronger than the $\mathrm{Si}-\mathrm{Cl}$ bond and the fluorinated chemistry for SiC CVD has remained poorly understood.

Using $\mathrm{SiF}_{4}$ as $\mathrm{Si}$ precursor in growth experiments combined with thermal equilibrium calculations of gas phase composition and quantum chemical computations of the surface chemistry first the silicon chemistry in the CVD process has been probed. It is shown that while growth rates on the order of $35 \mu \mathrm{m} / \mathrm{h}$ can be achieved with a fluorinated chemistry, the deposition chemistry is very sensitive to the mass flows of the precursors and not as robust as the chlorinated CVD chemistry which routinely yields $100 \mu \mathrm{m} / \mathrm{h}$ over wide conditions. By using the position for the onset of epitaxial growth along the gas flow direction as a new measurable, together with modeling, it is concluded that $\mathrm{SiF}$ is the main $\mathrm{Si}$ growth species with $\mathrm{SiHF}$ as a minor $\mathrm{Si}$ species contributing to growth.

The carbon chemistry in a fluorinated SiC CVD process has been probed by a similar approach. Here it is found that the slow kinetics of the 
$\mathrm{SiF}_{4}$ molecule needs to be matched by a carbon precursor with comparable slow kinetics. It is shown that methane is a suitable carbon precursor in combination with $\mathrm{SiF}_{4}$.

Before a fluorinated CVD chemistry can be adopted in device processing, the effect of fluorine on the dopant incorporation must be understood since dopant incorporation is of paramount importance in semiconductor manufacturing. Dopant incorporation studies for n-type doping with $\mathrm{N}$ using $\mathrm{N}_{2}$ and p-type doping with $\mathrm{Al}$ using TMAl in fluorinated CVD of homoepitaxial $\mathrm{SiC}$ are presented. It is found to be possible to control the doping in $\mathrm{SiC}$ epitaxial layers when using a fluorinated CVD chemistry for both $\mathrm{n}$ - and p-type material using the $\mathrm{C} / \mathrm{Si}$ ratio as in standard $\mathrm{SiC}$ CVD. However, large area doping uniformity seems to be a challenge for a fluorinated CVD chemistry, most likely due to the very strong Si-F and Al-F bonds. Furthermore, it is found that no additional optically or electrically active defects are created due to the use of fluorine in the CVD process.

Finally, the fluorinated chemistry is compared to the chlorinated and brominated chemistries for SiC CVD and an overall model for halogen addition to $\mathrm{SiC} \mathrm{CVD} \mathrm{is} \mathrm{presented.}$ 
POPULÄRVETENSKAPLIG SAMMANFATTNING

Elektronik har en viktig betydelse för människan idag. Elektronik hjälper oss att styra spänningar och strömmar. När dessa spänningar och strömmar är stora är dagens främsta material för elektronik, kisel, inte det bäst lämpade. Ett material som för detta ändamål har bättre egenskaper är kiselkarbid ( $\mathrm{SiC}$ ). Detta eftersom att $\mathrm{SiC}$ kan transportera stora strömmar genom en liten tvärsnittsyta utan att bli för varmt och klarar av höga spänningar över ett kort avstånd utan att kortsluta. Den idag uteslutande mest använda metoden för att tillverka de skikt av $\mathrm{SiC}$ som är de elektriskt aktiva är chemical vapor deposition (CVD).

CVD bygger på att gaser flödar genom en kammare där gaserna reagerar, och bildar nya molekyler och radikaler, varav vissa binder till det prov som är placerat i kammaren där det är avsett att skiktet ska tillverkas. Gaserna som flödar genom kammaren innehåller bland annat så kallade källmolekyler, som i fallet när $\mathrm{SiC}$ ska tillverkas innehåller kisel (Si) och kol (C). I källgaserna är Si och $\mathrm{C}$ bundet till andra grundämnen, vanligast väte eller klor. Det är ändå bara $\mathrm{Si}$ och $\mathrm{C}$ som fastnar i SiC-skiktet. Men väte och klor spelar en stor roll för hur $\mathrm{Si}$ och $\mathrm{C}$ beter sig - vilka Si-C-H-Cl-molekyler eller -radikaler som finns i gasfasen och slutligen binder till ytan.

Vad händer om klor byts ut mot fluor? Klor $(\mathrm{Cl})$ och fluor $(\mathrm{F})$ ligger i samma grupp i periodiska systemet (halogenerna) och kan därför antas reagera på liknande sätt. Dock binder $\mathrm{F}$ starkare än $\mathrm{Cl}$ till Si. Denna avhandling syftar till att ingående besvara denna ställda fråga. Det görs genom att kombinera experimentella resultat med resultat från olika sorters simuleringar. 
Vad som framkommit i arbetet är att $\mathrm{SiF}$, som förekommer i rätt liten utsträckning, är den huvudsakliga radikalen som får Si ner på ytan. F, som binder starkt till $\mathrm{Si}$, verkar i hög grad även binda till ytan på så sätt att $\mathrm{C}$ har svårt att binda till ytan och därmed fortsätta tillväxten av $\mathrm{SiC}$. Att Si och F binder starkt får som konsekvens att det är svårt att bryta bindningar som frigör Si för att odla skiktet. Detta måste källmolekylen som innehåller C anpassas för genom att väljas på ett sådant sätt att även $\mathrm{C}$ frigörs långsamt till skiktet. Förekomsten av $\mathrm{F}$ i systemet försvårar därmed tillväxten, men i övrigt följer F-kemin de mönster med inkorporering av dopämnen och defekter som gäller för andra kemierna. 
1. P. Stenberg, P. Sukkaew, I. Farkas, O. Kordina, E. Janzén, L. Ojamäe, Ö. Danielsson, H. Pedersen, "Silicon Chemistry in Fluorinated Chemical Vapor Deposition of Silicon Carbide", accepted; J. Phys. Chem. C, 2017, DOI: 10.1021/acs.jpcc.6b10849

2. P. Stenberg, Ö. Danielsson, E. Erdtman, L. Ojamäe, E. Janzén, $\mathrm{H}$. Pedersen, "Matching precursor kinetics to afford a more robust CVD chemistry: a case study of the $C$ chemistry for silicon carbide using $\mathrm{SiF}_{4}$ as Si precursor", submitted

3. P. Stenberg, H. Pedersen, E. Janzén, "Incorporation of dopants in epitaxial SiC layers grown with fluorinated CVD chemistry", submitted

4. P. Stenberg, I. D. Booker, I. G. Ivanov, R. Karhu, E. Janzén, "Defects in silicon carbide grown by fluorinated chemical vapor deposition chemistry", in manuscript

5. P. Sukkaew, P. Stenberg, O. Kordina, E. Janzén, H. Pedersen, L. Ojamäe, Ö. Danielsson, "Opening the black box of silicon carbide chemical vapor deposition", submitted 
1. I have planed the experimental work and done the main part of experiments as well as been actively involved the discussions regarding the simulations that were done in the study. I have interpreted the results and together with the co-authors written the manuscript.

2. I have planed and done all the experimental work as well as actively discussed the simulations within the study. I have interpreted the results and together with the co-authors written the manuscript.

3. I have planned the done all the experimental work. I have interpreted the results and together with the co-authors written the manuscript.

4. I have planned the study and grown the epitaxial layers that were characterized. Together with the co-authors I have interpreted the results and with them written the manuscript.

5. I have contributed with experimental experience (especially from the fluorinated chemistry), been involved in the scientific discussions and participated in the writing of the manuscript. 
This work here at IFM would not have been as it was if it wasn't for you, which I specially would like to thank.

My supervisors Erik Janzén and Henrik Pedersen for taking me through this and for giving me the chance to work on some challenging topics,

My colleges Rickard Liljedahl and Ildikó Farkas for the lunch breaks and countless coffee breaks,

Örjan Danielsson for interesting scientific discussions where a short question often became an hour of discussion,

The simulation group with Pitsiri, Örjan, Olle, Henrik, Lars and Edvin from which I have learnt so much,

My mentor Kenneth and the director of graduate studies Per-Olof for helping me with Ph.D. study related issues,

The examiners in the courses I've teached, Per and Calle,

My Ph.D. student friends and colleges, present and former: Christopher, Katarina, Björn, Ian, Pitsiri, Louise, Valdas and Jens,

My friends Sanna, Helena, Malin, Andreas, Pär and Klas for your support and help in so many different ways,

My parents and, last but not least, Lovisa, for your support, patience and love. 
XIV 
1 Introduction 1

1.1 Silicon carbide as a semiconductor . . . . . . . . . . . 1

1.2 Electronic devices . . . . . . . . . . . . . . . . 2

1.3 Silicon carbide for electronic devices . . . . . . . . . 2

1.4 Fluorinated SiC CVD . . . . . . . . . . . . . . . 3

2 Silicon carbide 5

2.1 Silicon and carbon . . . . . . . . . . . . 5

2.2 Building the $\mathrm{SiC}$ crystal . . . . . . . . . . . . 6

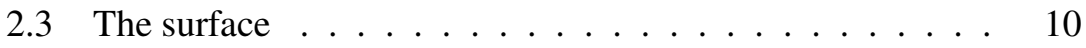

3 Growth methods 13

3.1 Physical vapor transport . . . . . . . . . . . . . . 13

3.2 Chemical vapor deposition $\ldots \ldots \ldots$

3.2 .1 Cold wall reactors . . . . . . . . . . . . . . . . . . 14

3.2.2 Hot filament reactors . . . . . . . . . . . . . . . 14

3.2 .3 Hot wall reactors . . . . . . . . . . . . . . . . 14

3.2.4 Horizontal or vertical gas flow . . . . . . . . 15

4 The horizontal hot wall CVD reactor 17

4.1 A CVD reactor . . . . . . . . . . . . . . . . . 17

4.2 The hot zone . . . . . . . . . . . . . 18

5 Effect of related process parameters 23

5.1 A SiC CVD process . . . . . . . . . . . . . . 23 
5.2 Physics related process parameters . . . . . . . . . . 24

5.3 Chemistry related process parameters . . . . . . 25

6 Modelling 27

6.1 Density functional theory . . . . . . . . . . . . . 27

6.2 Thermal equilibrium . . . . . . . . . . . . . . . 28

6.3 Kinetics . . . . . . . . . . . . . . . . . 28

7 Characterization $\quad 31$

7.1 Optical Microscopy . . . . . . . . . . . . . . . . . . 31

7.2 Scanning Electron Microscopy . . . . . . . . . . . . . . . . 32

7.3 Capacitance-Voltage measurements . . . . . . . . 32

7.4 Photoluminescence . . . . . . . . . . . . . . 33

8 Future work $\quad 35$

$\begin{array}{ll}\text { References } & 37\end{array}$

Summary of the included papers 4

$\begin{array}{ll}\text { Paper } 1 & 43\end{array}$

$\begin{array}{lr}\text { Paper } 2 & 65\end{array}$

$\begin{array}{lr}\text { Paper } 3 & 85\end{array}$

$\begin{array}{lr}\text { Paper } 4 & 93\end{array}$

$\begin{array}{ll}\text { Paper } 5 & 107\end{array}$ 


\section{CHAPTER 1 \\ INTRODUCTION}

Silicon Carbide $(\mathrm{SiC})$ is a semiconductor material at the same time being a hard material. Because of its hardness one application of $\mathrm{SiC}$ is as an abrasive. Here, however, the focus is on $\mathrm{SiC}$ as a semiconductor. It is often compared to Silicon (Si), which probably is the semiconductor today.

\subsection{Silicon carbide as a semiconductor}

Silicon Carbide $(\mathrm{SiC})$ is a semiconductor with properties suitable for electrical power devices. [1] Power devices are devices running at high voltages and/or currents. One of these suitable properties is the wide band gap (3.26 eV compared to $1.1 \mathrm{eV}$ for $\mathrm{Si}$ ). This gives the material a high electric break down field, i.e. how much voltage that can be applied over a certain material thickness. The electrically active layer in a SiC device can, thanks to this, be as thin as roughly $1 / 10$ of the equivalent $\mathrm{Si}$ device. [2] It also allows a $\mathrm{SiC}$ device to run at higher temperatures since fewer electrons will be thermally excited into the conduction band reducing leak currents. Another property that makes it attractive for high power devices is the high saturation electron drift velocity. [3] This allows more current per area in the device, which can reduce the areal size of the device. Yet another property that $\mathrm{SiC}$ posses is a high thermal conductivity [4] which makes it even more attractive as a power device since more generated heat from power losses can faster be conducted away from the electrical active area.

What is $\mathrm{SiC}$ not suitable for? $\mathrm{SiC}$ does not have as good properties as 
gallium nitride $(\mathrm{GaN})$ for LED and high frequency applications. That is because $\mathrm{SiC}$ has an indirect band gap. The high production costs makes it not competitive to Si devices for normal electronic applications.

To summarize $\mathrm{SiC}$ is good for electronic device applications involving high currents (e.g. bipolar transistors), high voltages (e.g. rectifying diodes), high temperatures and low frequencies.

\subsection{Electronic devices}

There are several different kinds of electronic devices. One of them is the transistor. The transistor is a component with which it is possible to control electric currents or voltages. It was invented in 1947 by John Bardeen, Walter Brattain and William Shockley. At that time it was made out of germanium $(\mathrm{Ge})$, but in 1954 the first silicon (Si) transistor was produced.

The electronic devices consist of differently doped layers with electrical contacts. In some cases there are also an insulating layer in between the contact and the doped layer. A diode consists of two layers, i.e. PN, and a transistor consists of three differently doped layers, i.e. NPN or PNP, where $\mathrm{N}$ is a layer doped with donors and $\mathrm{P}$ with acceptors. By applying a voltage over the first two layers, or a current to the middle layer, the voltage or current at the third layer can be controlled.

To be able to have the desired electric properties of the devices the amount of dopants in the different layers has to be correct as well as the thickness of the layer. One way of implanting these dopants is during the growth of the layer itself. That is why dopant incorporation during growth is important to control.

Dopants can be considered as defects in the crystal to alter its electrical properties. These defects are wanted. There are also non-wanted defects. These can be other elements or misplacements in the crystal, which can severely alter the electrical properties. Non-wanted defects originating from the $\mathrm{SiC}$ substrate has for long made $\mathrm{SiC}$ devices a challenge. [5]

To avoid other elements and dust, the electronic device manufacturing takes place in cleanrooms.

\subsection{Silicon carbide for electronic devices}

For the design of the electrical device, the correct material thickness and amounts of the desired defects are wanted. In order to do so a method with 
high degree of control over the process is needed. The supreme method which has become standard for $\mathrm{SiC}$ based devices is chemical vapor deposition (CVD) [6] described in more detail in chapter 3.2. Here, gases containing silicon and carbon are heated to react with a $\mathrm{SiC}$ surface in such a way that new $\mathrm{SiC}$ layers are formed in a controlled fashion on top of the previous, building a $\mathrm{SiC}$ epitaxial layer.

\subsection{Fluorinated SiC CVD}

To understand the process of building up a $\mathrm{SiC}$ epitaxial layer, a fundamental understanding of what is happening in a CVD system is needed. Different chemistries, i.e. what gases are used, in the CVD system produces widely different results. Adding chlorine to the $\mathrm{SiC}$ process has been shown to enhance growth. [7, 8] Chlorine $(\mathrm{Cl})$ is a halogen, and other halogens like fluorine $(\mathrm{F})[9,10]$ and bromine $(\mathrm{Br})[11]$ can also be added to the process with different effects.

This work has mainly been focusing on the fundamental understanding of the F chemistry - what gas species are formed, what gas species are depositing on the surface and how $\mathrm{F}$ chemistry compares to other chemistries. 


\section{CHAPTER 2}

SILICON CARBIDE

Silicon carbide is a crystal built up of silicon and carbon with every second atom being a silicon $(\mathrm{Si})$ atom and every second atom being a carbon $(\mathrm{C})$ atom. Every $\mathrm{Si}$ atom binds to four $\mathrm{C}$ atoms and every $\mathrm{C}$ atom binds to four $\mathrm{Si}$ atoms. This can, however, be done in several different ways, as will be described in chapter 2.2. Before that, some properties of the two elements $\mathrm{Si}$ and $\mathrm{C}$ will be pointed out.

\subsection{Silicon and carbon}

Both $\mathrm{Si}$ and $\mathrm{C}$ are group 14 elements - they have 4 valence electrons. The angle between two bonds become $109.5^{\circ}$. C is the smallest group 14 element with atomic number 6, and below it in the periodic table is Si with atomic number 14. $\mathrm{C}$ might be familiar from organic chemistry, but $\mathrm{C}$ bonded together by $\mathrm{sp}^{3}$-bonds also exists in crystal form known as diamond - which is a semiconductor. Diamond has even a larger band gap than $\mathrm{SiC}$. Si, which also takes the same crystal structure as diamond (the diamond structure) has a smaller band gap then SiC.

Table 2.1: Some properties of the chemical bonds related to $\mathrm{C}$ and $\mathrm{Si}$

\begin{tabular}{l|ccc} 
& $\mathrm{C}-\mathrm{C}(\mathrm{C})$ & $\mathrm{C}$-Si $(\mathrm{SiC})$ & $\mathrm{Si}-\mathrm{Si}(\mathrm{Si})$ \\
\hline Bond strength $(\mathrm{kJ} / \mathrm{mol})[12]$ & 618 & 447 & 310 \\
Bond length $(\AA)[13]$ & 1.53 & 1.87 & 2.33 \\
Band gap $(\mathrm{eV})[14,15]$ & 5.5 & $2.3-3.3$ & 1.1
\end{tabular}




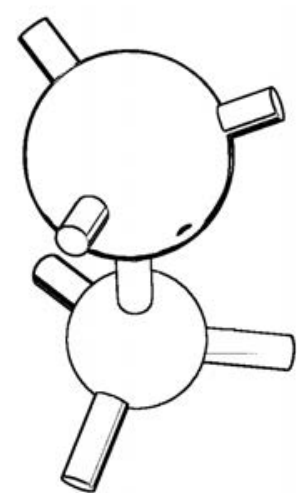

(a)

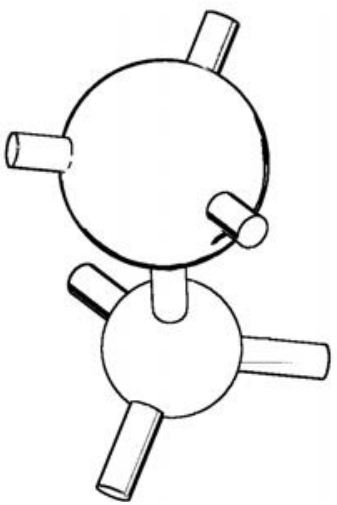

(b)

Figure 2.1: The two possible configurations for a $\mathrm{Si}$ and a $\mathrm{C}$ atom to bind to each other. $\mathrm{Si}$ is represented by the larger sphere on top, $\mathrm{C}$ is represented by the smaller sphere below and the chemical bonds represented by the sticks. a) Hexagonal configuration. The bonds are pointing in the same direction. b) Cubic configuration. The bonds are pointing in the opposite direction.

\subsection{Building the SiC crystal}

$\mathrm{SiC}$ posses a property called "polytypism". That is how the $\mathrm{Si}$ and $\mathrm{C}$ atoms are stacked before the order is repeated. There are two ways of stacking a $\mathrm{Si}$ and a $\mathrm{C}$ atom together shown in Figure 2.1 - either the bonds point in the same direction, which is referred to as the hexagonal configuration (h), or they can point as much away from each other as possible, which is the cubic configuration $(\mathrm{k})$.

From this way of describing bonds it might be possible to imagine that since the bonds are closer to each other in the hexagonal configuration, the electronic repulsion is stronger here than in the cubic configuration, where they are farther from each other. This can be used to get an estimate of the band gap in different polytypes of $\mathrm{SiC}$ - higher degree of hexagonal configuration gives a higher band gap, while higher degree of the cubic configuration gives a lower band gap, seen as the spread in Table 2.1.

However, this way of describing the stacking will make the surface termination a bit unintuitive, because when referring to the $\mathrm{SiC}$ crystal's different faces, the face refer to the atom with one bond out (i.e. normal to the surface) and the other atom is known as its termination. What is shown in Figure 2.1 is a $\mathrm{Si}$ terminated $\mathrm{C}$-face, assuming the top surface in the 


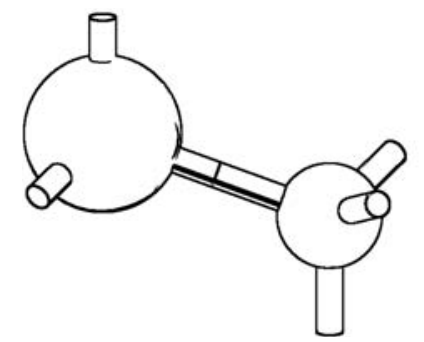

Figure 2.2: The cubic configuration rotated. Upwards the non-terminated $\mathrm{Si}$-face and downwards the non-terminated $\mathrm{C}$-face.

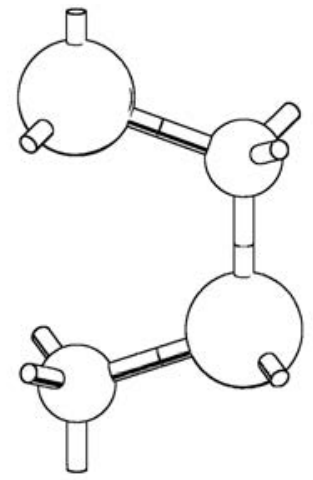

(a)

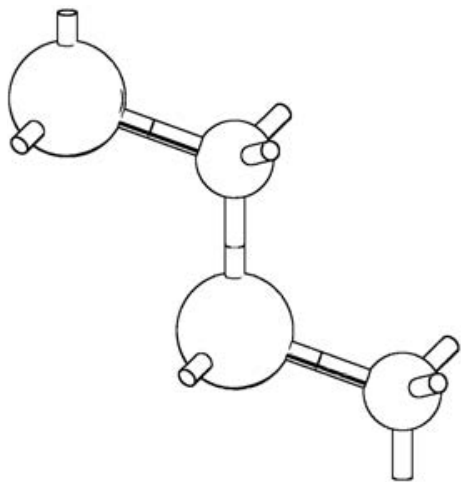

(b)

Figure 2.3: Again, the two possible configurations for a $\mathrm{Si}$ and a $\mathrm{C}$ atom to bind to each other. a) Hexagonal configuration. b) Cubic configuration. The lower $\mathrm{Si}$ atom is rotated to have the same configurations as in Figure 2.1.

horizontal plane. By instead only using the cubic configuration block, the surface, and its termination can be more easily recognised.

In Figure 2.2, a surface at the top of the $\mathrm{Si}$ atom can be imagined if the $\mathrm{Si}-\mathrm{C}$ unit is repeated. This would build up the cubic polytype of SiC. If now two $\mathrm{Si}-\mathrm{C}$ units are joined together, and of which the lower $\mathrm{Si}$ atom is rotated to have the same configurations as in Figure 2.1 with the $\mathrm{C}$ atom above - the hexagonal configuration. This is shown in Figure 2.3a. This unit repeated would build up the hexagonal polytype - the $100 \%$ hexagonal polytype. The cubic SiC polytype with $2 \mathrm{Si}-\mathrm{C}$ units is shown in Figure 2.3b.

There can be arbitrary combinations of hexagonal (h) and cubic (k) units. A common polytype today though is the "hk" polytype (the sequence hk repeated), used to compare $\mathrm{SiC}$ to $\mathrm{Si}$ in chapter 1.1, shown in Figure 2.4. 


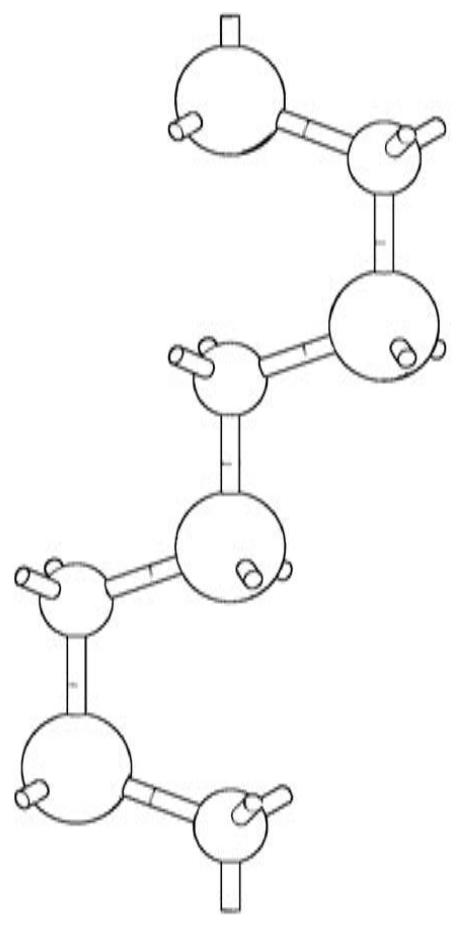

Figure 2.4: The 50\% hexagonal poltype. Every second unit is hexagonal and every second unit is cubic.

Every second layer of Si-C units is hexagonal, and the polytype is therefore $50 \%$ hexagonal. Its bandgap is in between the purely hexagonal and the cubic polytype.

So far the view of the $\mathrm{Si}-\mathrm{C}$ units has been from the side, viewing the so called c-direction which then goes vertical (from the C-face to the Si-face). Now taking a top view, facing towards the c-direction, one bilayer of $\mathrm{SiC}$ (Si-face) would look like Figure 2.5a, with one bond from the Si facing up, and one bond from the carbon facing down (thereby not seen from a top view). This view can resemble how adatoms in growth experience the surface/crystal as they are placed on top the previous layer. The next layer can have two different orientations. Either it is a similar layer, which would position the next $\mathrm{Si}$ atoms above the void of the hexagon as in Figure 2.5b $(A B)$, or above the carbon atoms of the previous layer (AC). From here the $\mathrm{AB}$ and $\mathrm{AC}$ may look similar. Eventually, just stacking $\mathrm{ABs}$ on top of each other would create an equivalent stacking as ACs on top of each other just rotated $120^{\circ}$. These positions were only taken as starting definitions for 


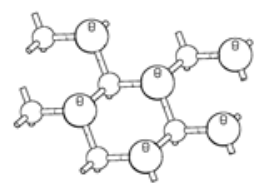

(a)

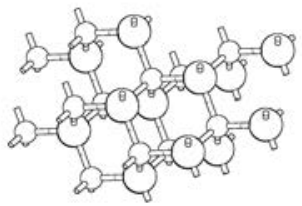

(b)

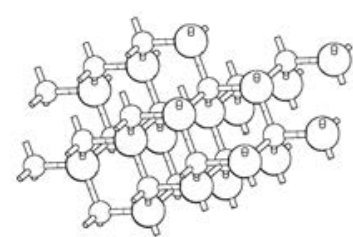

(c)

Figure 2.5: Stepwise stacking of bilayer. Here the formation of the $A B C$ stacking with a) one bilayer in A position, b) two bilayers in the $A B$ positions, c) three bilayers in the $\mathrm{ABC}$ postions.

how next layers relate to each other. From the $\mathrm{AB}$ stacking the next bilayer can be positioned such that the $\mathrm{Si}$ atoms again will be in the voids of the previous layer which is above the carbon atoms of the first layer, referring to the $\mathrm{C}$ position thereby becoming an $\mathrm{ABC}$-stacking (Figure (2.5c), or such that the $\mathrm{Si}$ atoms are above the previous layer's carbon atoms, which were above the first layer's $\mathrm{Si}$ atoms corresponding to the A position, thereby having an ABA stacking. The ABC stacking corresponded to always put the next layer's $\mathrm{Si}$ atoms in the void of the previous layer's hexagon. The next stacking in the same way would then be above equal to the A position and the $\mathrm{ABC}$ would the repeat. If the next layer from the ABA stacking would be at the $\mathrm{B}$ position there would be an $\mathrm{ABAB}$ stacking, or just $\mathrm{AB}$ stacking repeated.

It can here be noted that this letter nomenclature corresponds to adding or subtracting 1 in a modulus 3 fashion. $1+1=2,2+1=3,3+1=4 \rightarrow 1$, $1-1=0 \rightarrow 3$.

Here, a continuation in letters (e.g. $\mathrm{ABC}$ and $\mathrm{CBA}$ ) corresponds to a cubic unit (k), while a swap back (e.g. ABA and BAB) corresponds to a hexagonal unit (h). C to A is a continuation. The previously mentioned hk stacking (hkhkhk...) is equal to kh (permuted one step) could then be written as $\mathrm{ABCB}$, which would then repeat ( $\mathrm{ABC}$ is a continuation (cubic) and $\mathrm{BCB}$ is a swap back (hexagonal)). Except for the stacking $\mathrm{ABC}$, this notation tells how many bilayers there are in the unit cell of the polytype. $\mathrm{AB}$ has 2, $\mathrm{ABCB}$ has 4, while $\mathrm{ABC}$ has 1 because it is a Si-C unit repeated.

Although the notation of using $h$ and $k$, called the Jagodzinski notation [16], is useful when predicting the band gap, and using the position of the atoms relative to each other denoted $\mathrm{A}, \mathrm{B}$ and $\mathrm{C}$ can predict the size of the unit cell, probably the most common notation is the so called Ramsdell notation. [17] It does not say whether the hexagonality is $100 \%$ or $50 \%$ 
or what the exact stacking sequence is, but states how many Si-C layer there before the letter sequence is repeated together with if the polytype is cubic $(\mathrm{C})$, hexagonal $(\mathrm{H})$ or rhombohedral $(\mathrm{R})$. The ABC stacking, which is cubic is in Ramsdell's notation denoted $3 \mathrm{C}$, while $\mathrm{AB}$ and $\mathrm{ABCB}$ are hexagonal denoted $2 \mathrm{H}$ and $4 \mathrm{H}$ respectively. The rhombohedral structure appears when the stacking sequence has incremented one cycle, i.e. a subset of the sequence increment one letter. $15 \mathrm{R}$ is such a polytype. The order

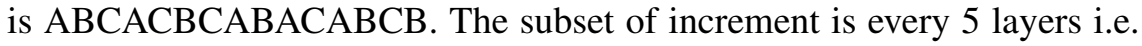
ABCACBCABACABCB. It can be written in the Jagodzinski notation as $(\mathrm{kkhkh})_{3}$. By this way of looking at a rhombohedral sequence, Ramsdell also points out that $3 \mathrm{C}$, written as $\mathrm{ABC}$ can be thought of as a rhombohedral structure. [17]

In this work the $4 \mathrm{H}$ polytpye, or the hk polytype, was used in growth. These sites can be recognized for instance when characterizing doped layers using photoluminescence (chapter 7.4), since a dopant atom will be positioned at a different energy level compared to the conduction band depending on if it is incorporated at a cubic or hexagonal site.

\subsection{The surface}

Previously the two faces Si-face and C-face were mentioned. The Si-face was in the direction where one bond from the (each) Si atom pointed out from the crystal, and at the other end of the crystal the C-face was found, where one bond from each $\mathrm{C}$ atom pointed out.

The difference in growing on the Si-face or the C-face appear when the different monolayers grow. When growing on the Si face, one bond per $\mathrm{Si}$ atom points for the $\mathrm{C}$ atoms to attach to. The $\mathrm{C}$ atoms then bond with one bond to the Si layer, then having three bonds each pointing out for the $\mathrm{Si}$ atoms to attach to. When growing on the $\mathrm{C}$ face, one bond per $\mathrm{C}$ atom points for the $\mathrm{Si}$ atoms to attach to. The $\mathrm{Si}$ atoms then bond with one bond to the $\mathrm{C}$ layer, then having three bonds each pointing out for the $\mathrm{C}$ atoms to attach to.

Previously it was mentioned that dopants take differents sites. The so called "site competition theory" [18] suggests that nitrogen $(\mathrm{N})$ atoms take $\mathrm{C}$ sites, while aluminium ( $\mathrm{Al}$ ) atoms take $\mathrm{Si}$ sites. Growing on the $\mathrm{C}$-face, where $\mathrm{Si}$ will have 3 bonds out for the $\mathrm{C}$ layer, $\mathrm{N}$ will be more likely to adsorb than growing on the Si-face. Growing on the Si-face will therefore create a lower background doping $\mathrm{N}$.

An adatom coming down on the surface can migrate on the surface before it either leaves the surface or find a position where it is stabilized. To 
enhance growth a surface where adatoms are stabalized are preferred. Such a position can be where multiple bonds bind to the adatom. Such a surface can be created by polishing the surface so that it becomes slightly tilted compared to the c-direction. The tilt is referred to as the off-cut angle, where $0^{\circ}$ corresponds to no tilt, i.e. the surface has the c-direction as its normal. In this work, substrates (i.e. the crystal that the epitaxial layer has been grown on) have had an off-cut angle of $4^{\circ}$. The tilt is in the 1120-direction, which is the direction where most bonds get exposed. 


\section{CHAPTER 3}

GROWTH METHODS

In this chapter two significantly different approaches to grow silicon carbide will be given. Physical vapor transport, which for $\mathrm{SiC}$ is used to grow boules that will be sliced into wafers, and chemical vapor deposition, mainly used to grow the active layers in devices.

\subsection{Physical vapor transport}

Physical vapor transport (PVT) makes use of the flux originating from the temperature difference of two surfaces. A hotter surface evaporates more than a cold surface, and therefore a flux of gas species from hotter to the colder appear.

The basics for SiC PVT is a volume in which $\mathrm{SiC}$ powder (small crystals) have been put, above which (with a small gap) a seed SiC crystal has been placed, and over the gap a temperature gradient has been applied at high temperatures. This is referred to as seeded sublimation growth. This technique was improved by Tairov and Tsvetkov [19] and later lead to the first commercial $\mathrm{SiC}$ wafer from Cree Research Inc.

\subsection{Chemical vapor deposition}

The chemical vapor deposition (CVD) incorporates growth techniques that have in common that the precursors enter the growth cell in gaseous form and start gas phase reactions and/or surface reactions to grow the material. The machine in which the CVD is done is often referred to as a reactor. 
The reactions in the reactor can then be enhanced in different ways - e.g. enhanced by heat, as in thermal enhanced CVD or enhanced by energy as in laser or plasma enhanced CVD.

Here, however, the thermal CVD has been of interest. There are different flavours of thermal enhanced CVD. Some of them are briefly described below.

\subsubsection{Cold wall reactors}

By having a CVD reactor where only the substrate and its holder are heated, the gases are predominantly heated above this surface, forming growth species and react with the surface resulting in growth. The reactor walls are cold since they will only be passively heated, e.g. by the radiation from the substrate and the substrate holder, giving the reactor type its name - cold wall reactor.

The large thermal gradients that appear above the substrate can drastically change the gas phase composition at heights as small as 0.1 $\mathrm{mm}$. [6] This can result in more directed deposition of the precursors, creating less parasitic deposition, but it has a risk of creating high thermal gradients in the substrate due to that irradiation mainly cools the surfaces.

\subsubsection{Hot filament reactors}

Instead of having a hot substrate and cold gas as in the cold wall reactors, a reactor can be constructed by heating gases just before the substrate by letting them pass through a hot filament (or hot wires). This creates the growth species at the hot filament which can then hit a significantly colder substrate. One benefit with this method is that substrates not withstanding a high temperature can be used in the growth. For example, this has been done using $\mathrm{SiF}_{4}+\mathrm{CH}_{4}$ to grow polycrystalline $3 \mathrm{C}-\mathrm{SiC}$ on $\mathrm{Si}$ substrates. [20]

\subsubsection{Hot wall reactors}

The hot wall reactor got its name from that it, compared to the cold wall reactor also has hot walls around the substrate. By this, irradiation heats the substrate reducing thermal gradients. For a $\mathrm{SiC}$ process this also require less power since less power is lost to radiation. [21] The hot walls also heat the gas mixture creating growth species already prior to the substrate. The hot wall reactor will be described further and in more detail in chapter 4 , where a more complete description of a CVD system will be given as well. For 
a SiC process, temperatures in the range $1500{ }^{\circ} \mathrm{C}$ and $1700{ }^{\circ} \mathrm{C}$ are usually used. Compared to the cold wall reactor, the hot wall reactor can operate in a larger process window. [6]

\subsubsection{Horizontal or vertical gas flow}

There are many flavors of CVD reactors. One more dimension of this is if the gas flow is horizontal or vertical. For vertical, the gas flow can be directed upwards or downward. This affects the gas flow dynamics, where the downward direction has shown to yield higher growth rate and better dopand uniformity. [22] 


\section{CHAPTER 4}

\section{THE HORIZONTAL HOT WALL CVD REACTOR}

So far, a couple of different concepts for the so called hot zone have been presented. The hot zone will be discussed in detail in chapter 4.2 focusing on the horizontal hot wall CVD system in this work. But a CVD reactor is much more than just the hot zone. Therefore chapter 4.1 will give a brief overview of what more there is in a CVD system.

\subsection{A CVD reactor}

A CVD system is a complicated system with many different components. To more easily get an overview of a CVD system it can be divided into a couple of subsystems, briefly described below, each with a specific task.

- A gas system providing the correct amount of gases to the right gas line at the right time, e.g. precursors to the growth cell when growth starts. This is done by valves, regulators, mass flow controllers (MFCs) and electric pressure controllers (EPCs).

- A vacuum system taking care of the gases either they go via the growth cell or not. The vacuum is provided by vacuum pumps. To increase conductivity of the gas, especially at low pressure, the vacuum system is generally built using wide tubing. The vacuum system is not necessarily a subsystem - the functionality can be incorporated in the gas system, removing the fuzzy line where the gas system stops and the vacuum system takes over. One important feature here is the scrubber, which can be a so called burner or can 
be a scrubber using an adsorbent which adsorb the hazardous process gases.

- The growth cell is where the hot zone is, which is where the growth takes place. The growth cell encapsulates the hot zone as well as reduces turbulence in the gas flows prior to entering the hot zone.

- The heating system provides the hot zone with the heat for the chemical reactions. Here it is done by an electric coil creating a magnetic field in the hot zone, resulting in a circulating electric current in the hot zone, which turns into heat.

- There can also be a control system controlling the other subsystems, both automatic and by the operator, as well as managing interlocks reducing the risk for the operator to give detrimental commands to the reactor (e.g. let gases go in to the wrong gas line at the wrong time). There can also be automatic shut down of the CVD system if an accident occurs.

- Depending on reactor design there can also be a cooling system to keep certain parts cool, e.g. a quartz tube, electric coil or flanges with O-rings, which cannot withstand the high temperatures created during process.

The subsystems together form the CVD system and provides what is necessarily to grow $\mathrm{SiC}$ in the hot zone.

\subsection{The hot zone}

It is in the hot zone where the flowing gas gets heated. When the gas heats up, chemical reactions begin forming growth species. If the growth species hit the surface it can be adsorbed by surface reactions.

Figure 4.1 shows a drawing of the hot zone. The hot zone consists of mainly two things; a susceptor and an insulation. Depending on design, the power from an external magnetic field is either suscepted by the susceptor or, as in the design used in this work, an extra part surrounding the susceptor which absorbs the power, turning it into heat, which then transfer the heat to the susceptor by radiation as well as thermal contact. The insulation pieces surrounding the susceptor reduces the amount of heat leaving the susceptor.

As process temperatures are high the supreme material for the design of susceptor, heating ring and insulation is graphite. This graphite has though other elements incorporated (where boron (B) is the main issue today) and is not pure enough to be used directly where the $\mathrm{SiC}$ sample is exposed to the graphite. This mainly concerns the susceptor, which is therefore a SiC 


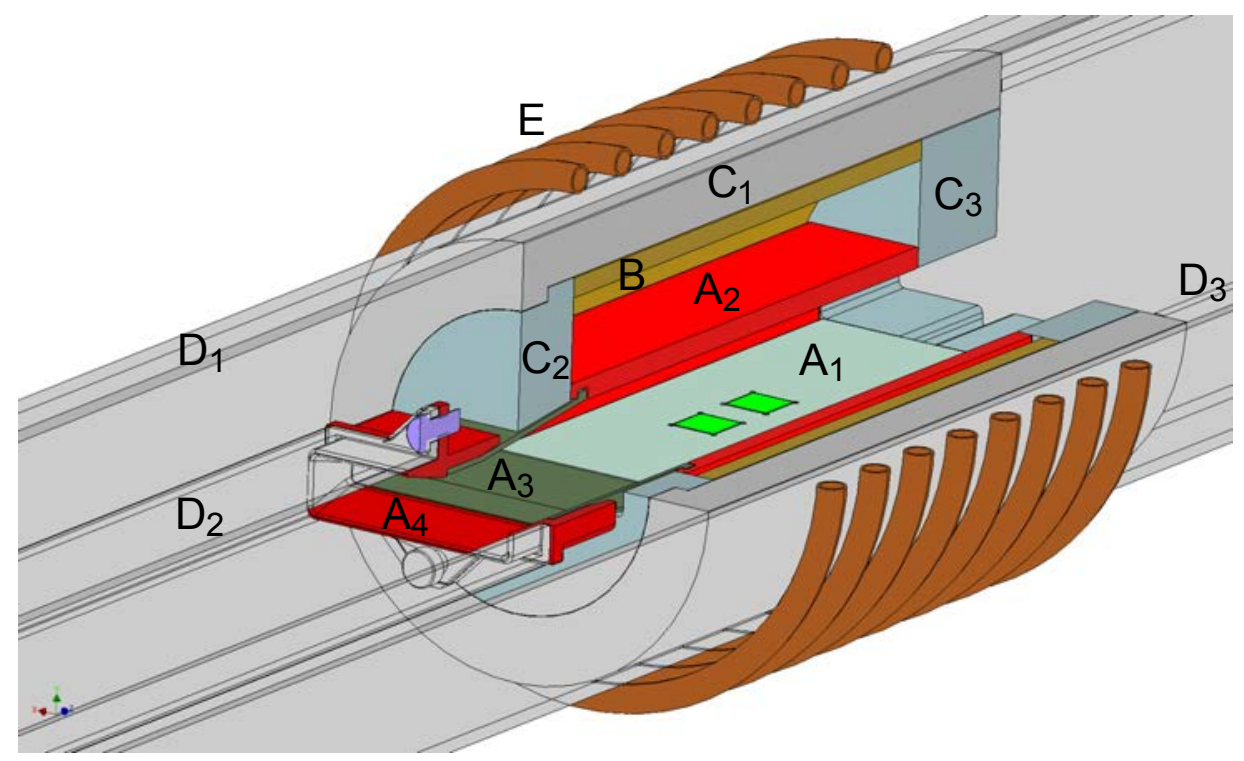

Figure 4.1: Three-quarter section view of the hot zone for the horizontal hot wall reactor used in this work. The susceptor consists of a bottom part $\left(\mathrm{A}_{1}\right)$ where the substrates are placed, a top part $\left(A_{2}\right)$ and a susceptor inlet $\left(A_{3}\right)$. It is inside here the process gases flow (in this figure from left to right). To heat the susceptor, a heating ring (B) is transferring the magnetic field, provided by the electric coil (E), into heat. The susceptor and the heating ring are surrounded by rigid graphite insulation $\left(\mathrm{C}_{1}, \mathrm{C}_{2}, \mathrm{C}_{3}\right)$ as well as a thermal break $\left(\mathrm{A}_{4}\right)$ upstream of the susceptor inlet. The parts labeled $\mathrm{A}, \mathrm{B}$ and $\mathrm{C}$ forms the hot zone. The hot zone is encapsulated in a quartz tube $\left(D_{1}\right)$. To further enhance the gas flow into the hot zone, a quartz gas liner $\left(D_{2}\right)$ is mounted. On the exhaust side an inner quartz tube $\left(D_{3}\right)$ is placed to increase protecting for the outer quartz tube from deposition and heat, as well as reducing turbulence in the susceptor due to the fast change in gas cross section. 
coated as delivered. For the insulation, a rigid graphite is used.

The heating of the hot zone in this set-up is using an electric coil, which generates a magnetic field inside the hot zone. This results in a force on the electrons in the graphite. Since the graphite makes a complete circuit (i.e. the graphite ring), the electrons can create a circular current in the graphite ring. Due to the resistance in the material, heat is created.

The rigid graphite, used as insulation, has its fibres mainly perpendicular to the direction of which isolation is desired. Therefore, different fibre directions are used depending on where the isolation piece is situated. For the insulation outside the heating ring, the fibres should be perpendicular to the radial direction, while in the front and the rear, the fibres should preferable be in a radial plane. The insulation keeps the quartz tube surrounding the hot zone from melting, as $\mathrm{SiC}$ process temperatures are well above what the quartz should be exposed to not to break.

The susceptor should preferable have low temperature gradients in the susceptor while operating at process temperatures. The process gases entering the susceptor via the susceptor inlet are cold and get heated up along their path through the susceptor. This results in a larger cooling effect from the gas at the susceptor inlet than at the rear. To compensate for this, the susceptor inlet is tapered to reduce cooling caused by radiation. The angle on the tapering susceptor inlet must though be small to avoid turbulence in the gas. A turbulent gas flow will locally let more gas species pass which can result in uneven deposition rates.

Prior to the susceptor inlet is a thermal break to stop heat by conduction in a solid material by a poor material contact to the thermal break. The thermal break is further connected to a quartz gas liner. It is inside this liner which the process gases travel before entering the susceptor. While travelling through the liner, the desired laminar flow is stabilized after exiting the narrow gas pipes in the gas system.

Outside of the quartz gas liner, but still inside the quartz pipe, is another gas flow which is supposed to go through the insulation of rigid graphite. This gas flow consists of argon (Ar) gas, while the process gases mainly consist of hydrogen $\left(\mathrm{H}_{2}\right)$ gas. Ar has lower thermal conductivity than $\mathrm{H}_{2}$. By suppressing $\mathrm{H}_{2}$ from passing the insulation, ideally exchanging it to $\mathrm{Ar}$, the insulation properties of rigid graphite are further improved. Since connections between the parts are not gas tight, but rather loose, $\mathrm{H}_{2}$ still slips trough the insulation.

The gas flow of process gases going trough the susceptor creating $\mathrm{SiC}$, will also create and carry particles downstream of the hot zone depositing 


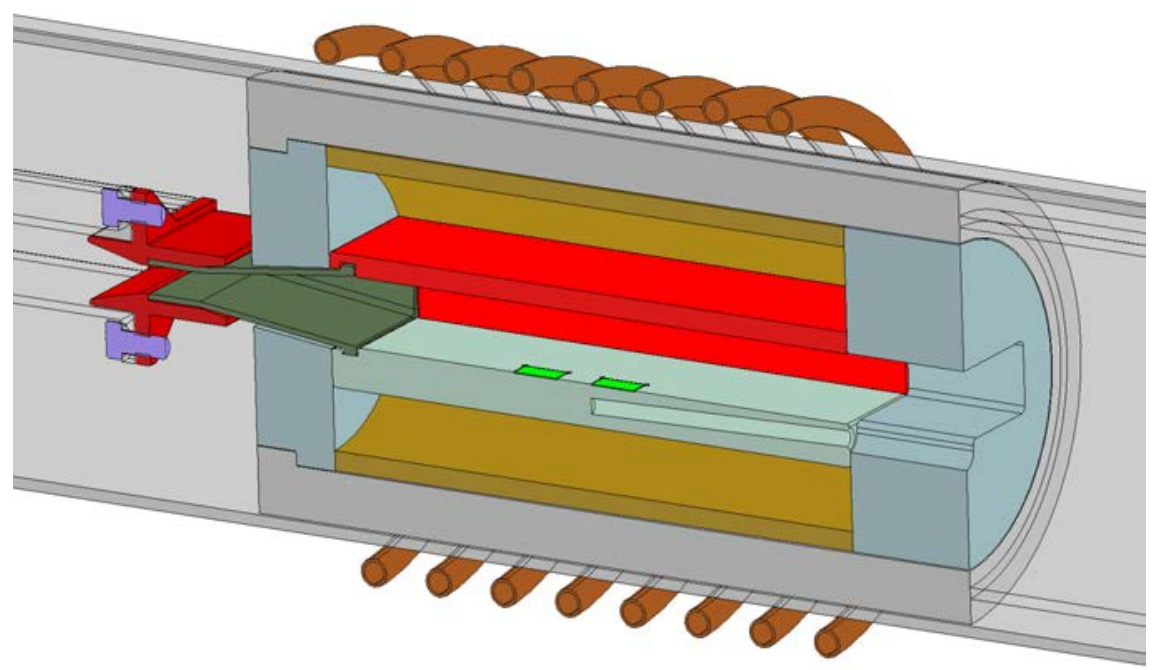

Figure 4.2: Half section view of the hot zone for the horizontal hot wall reactor used in this work, exposing the pyrometer hole drilled from the back in the susceptor.

on all surfaces, e.g. quartz and pipes. To avoid this happening on the quartz pipe, an inner quartz pipe is placed at the rear inside the quartz pipe. This quartz pipe can be taken out on run-to-run basis to get cleaned. The smaller radius on this inner quartz pipe compared to encapsulating quartz pipe also reduces turbulence to develop already inside the susceptor, due to the abrupt change in cross section for the gas flow.

To measure the process temperature a tool called pyrometer is used. The pyrometer measures the intensity of light at one or two certain frequencies for converting intensity to temperature. All objects emit electromagnetic radiation, where the intensity as a function of frequency depends on the temperature and emissivity of the object (according to Planck's law). A two color pyrometer measures the ratio between the intensity, from which the temperature can be derived, thereby not having to take the emissivity into account. A one color pyrometer on the other hand uses the absolute intensity of the radiation, taking the emissivity into account, to derive the temperature. The pyrometer used in this work was a one color pyrometer with a spot size of $4 \mathrm{~mm}$.

The susceptor bottom is designed with a $6 \mathrm{~mm}$ hole drilled into it, about $10 \mathrm{~cm}$ deep, called the pyrometer hole (Fig. 4.2). The pyrometer is directed such that it collects the light emitting from pyrometer hole. In such a cavity 
as this, the light can be reflected multiple times inside the hole before it hits the pyrometer. Doing so the emissivity approaches 1 , thereby reducing the error from the emissivity. At process temperature an emissivity error of 0.02 corresponds to an error of $10{ }^{\circ} \mathrm{C}$. The temperature in the pyrometer hole can be expected to be somewhat higher than at the susceptor surface due to the temperature gradient caused by the cooling gas on the inside and the heating ring on the outside. Furthermore, the sample does not have perfect contact with the susceptor, why it is even cooler. 


\section{CHAPTER 5}

EFFECT OF RELATED PROCESS PARAMETERS

In chapter 3.2 it was discussed how different ways of initiating chemical reactions gave the type of CVD its name, e.g. hot wall CVD. Temperature - as in thermal CVD - gives the molecules the vibrational energy to break a bond, but it also gives the molecules, or atoms velocity to overcome the activation energy to form a new bond. A suitable temperature therefore depends on what it should used for. If there are strong bonds that should be broken, a high temperature is preferred, but risk that less weaker bonds form because they will break faster. For adsorbed gas species on a surface, a tuned temperature can break and form bonds in such a manner that the gas species become mobile on the surface, promoting epitaxial growth rather than polycrystalline growth. A too high temperature on the other hand will break the bonds, making the surface species desorp from the surface.

There are several parameters effecting the growth and doing so in different, or multiple, ways. Here the parameters are divided into "physical" and "chemical" parameters, although there is no straight line in what should be considered as physical and chemical. However, a typical $\mathrm{SiC}$ process will first be discussed to be followed by a discussion on how the process parameters effect it.

\subsection{A SiC CVD process}

A typical $\mathrm{SiC}$ process in a hot wall CVD reactor consists of a so called carrier gas, which is hydrogen gas $\left(\mathrm{H}_{2}\right)$, in which so called precursors are 
diluted. Precursors are the gases containing the elements that are supposed to adsorb on the surface during growth, e.g. $\mathrm{Si}, \mathrm{C}$ and sometimes dopant atoms.

When the carrier gas together with the precursors enter the hot zone first the susceptor inlet and later the susceptor itself - they begin to heat up from the hot walls. It is only these mentioned surfaces that heat the gas. The gas is therefore warmest closest to the surface. When the gas heats up, chemical reactions start to take place. Some of the newly formed gas species can, by chemical reactions, adsorb on the surface. If they do so without desorbing from the surface, they will contribute to the crystal growth. Most of the gas species will though pass through the hot zone without adsorbing on the surface.

Typical Si precursors are $\mathrm{SiX}_{\mathrm{x}} \mathrm{H}_{4-\mathrm{x}}$ where $\mathrm{x}=0$ - 4 and $\mathrm{X}$ is a halogen - preferable $\mathrm{Cl}$ but was in this work exchanged for $\mathrm{F}$ where also $\mathrm{x}$ was equal to 4, i.e. the $\mathrm{Si}$ precursor was $\mathrm{SiF}_{4}$. As $\mathrm{C}$ precursor, typically a light hydrocarbon is used $-\mathrm{C}_{3} \mathrm{H}_{8}, \mathrm{C}_{2} \mathrm{H}_{4}$ or even $\mathrm{CH}_{4}$. The precursors are normally diluted to less than $1 \%$ in $\mathrm{H}_{2}$. Typically, this is given as the fraction of $\mathrm{Si}$ in $\mathrm{H}_{2}$, e.g. $\mathrm{Si} / \mathrm{H}_{2}=0.25 \%$, while the amount of $\mathrm{C}$ is then related to the amount of $\mathrm{Si}$ in a $\mathrm{Si} / \mathrm{C}$ ratio, which is normally in the order of 1 . The temperatures for a $\mathrm{SiC}$ process is normally around $1500-1800{ }^{\circ} \mathrm{C}$ at a process pressure in the order of $100 \mathrm{mbar}(\approx 1 / 10$ of atmospheric pressure). [7]

The amount of hydrogen is such that the average gas velocity becomes in the order of $10^{1} \mathrm{~m} / \mathrm{s}$ when pressure is taken into account.

\subsection{Physics related process parameters}

Pressure is a parameter that has several effects. If the pressure is reduced the mean free distance between particles increase, thereby the time between collisions, thereby reducing the reaction rate. The lower pressure also decreases the partial pressure of species thereby reducing the impingement rate of growth species on the surface, decreasing the growth rate. A higher pressure increases the thermal conductivity of the gas which affects thermal gradients in the hot zone and can also give rise to a higher quartz tube temperature, limiting the process window or put higher demands on reactor design. It also affects the gas velocity - a lower pressure increases the gas velocity, which in turn has other effects.

The pressure together with gas flow $\left(\mathrm{m}^{3} / \mathrm{s}\right)$ in a certain cross section $\left(\mathrm{m}^{2}\right)$ gives rise to an average gas velocity $(\mathrm{m} / \mathrm{s})$. But due to sheer friction in the gas, a gas velocity that is low enough to be laminar results in a so 
called boundary layer where the velocity is even lower than the average gas velocity, which is reduced for a higher gas velocity. How the gas velocity boundary layer thickness changes over a flat surface, e.g. a susceptor, is described in equation 5.1 below

$$
\delta \sim \sqrt{\frac{\mu x}{\rho U_{\infty}}}
$$

where $\delta$ is the boundary layer thickness, $\mu$ the viscosity of the gas, $x$ the distance along a surface, $\rho$ the density and $U_{\infty}$ the bulk gas velocity. [23]

The gas velocity and the pressure influences the cold finger, i.e. the temperature gradient in the gas and thereby the gas species concentration along the susceptor. Temperature gradients in the susceptor along the gas flow direction are small compared to the gradients normal to the susceptor surface, and therefore there are large species concentration gradients in these directions.

The substrate itself also effects the growth. The orientation of the crystal, with either $\mathrm{Si}$ or $\mathrm{C}$ face results in either one bond per surface site for the $\mathrm{C}$ growth species and three bonds for the Si growth species or three bonds per surface site for the $\mathrm{C}$ growth species and one for $\mathrm{Si}$ growth species. More bonds generally enhance adsorption. Either the Si growth species get this benefit, or the $\mathrm{C}$ species do.

The off-cut angle of the substrate changes the atomic step concentration. Due to a higher concentration of chemical bonds at the steps there is a higher possibility for adatoms to stick at the step than on a terrace, where the adatom's bond can more easily break (depending on the temperature) and leave the surface. The discovery of using off-cut samples helped to reduce the growth temperature as well as improve the quality of the grown material. [24]

\subsection{Chemistry related process parameters}

One of the probably most obvious parameters that effects the growth is the amount of precursors put in, i.e. how much $\mathrm{Si}$ and $\mathrm{C}$ are put in. Previously the gas flow was mentioned. The gas flow consists of a carrier gas and the precursors. The choice of precursors are of great importance for the adsorption of $\mathrm{Si}$ and $\mathrm{C}$ on the surface. Different precursors form growth species at different rates. This changes the gas phase composition and the impingement of growth species on the surface. At the same time the growth species have different likeliness to adsorb. 
Depending on how much of $\mathrm{Si}$ and $\mathrm{C}$ is diluted in the carrier gas, the growth rate can be limited by either the amount of $\mathrm{Si}$ or the amount of $\mathrm{C}$, i.e. if the growth rate varies if the amount of one of them is varied. This is known as Si-limited or C-limed growth. When doping the epitaxial layers, the incorporation efficiency of different dopants differs depending on how much available Si and C there are. This is further described for the fluorinated chemistry in Paper 3.

The amount of halogens play an important role in the gas phase as well as on the surface. In the gas phase the halogens help to reduce homogeneous nucleation of $\mathrm{Si}$, also know as silicon droplets, which appears if a too high concentration of Si precursor is used. Silicon droplets on the surface makes the epitaxial layer not usable for devices. A halogenated chemistry therefore allows for higher concentration of precursors, thereby increasing the growth rate.

On the surface, however, the halogens can terminate the $\mathrm{SiC}$ surface thereby reducing the growth rate. For the case of $\mathrm{F}$ this is a prominent effect, described in Paper 2. 


\section{CHAPTER 6 \\ MODELLING}

Many conclusions drawn in this work was done by comparing findings from experiments with results from modelling. Although modelling was not a part of this thesis work, this chapter briefly describes three of the modelling methods used in papers $(1,2,5)$ (Three, Sir!) included in this thesis.

In the hot zone there are both gas phase reactions as well as surface reactions taking place. These reactions and the gas phase composition can be modelled by different methods, described briefly below.

\subsection{Density functional theory}

Density function theory (DFT) is a method in quantum chemistry to calculate the energy of a many-body system, like a molecule. The name origins from that the method uses the electron density of the system to calculate the energy using different functionals. For example, two functionals that have been used in calculating the Gibbs free energy of reaction related to chemical reactions in $\mathrm{F} \mathrm{SiC} \mathrm{CVD} \mathrm{are} \mathrm{B3LYP}[25,26]$ and M06 [27].

When the Gibbs free energy of reaction has been calculated from DFT, the result can be used in other modelling, for instance thermodynamic equilibrium and kinetic simulations of the gas phase. It is also possible to achieve the activation energy of a reaction by calculating the Gibbs free energy for the transition state. Since the DFT calculations are often used for further modelling, it is of great importance that these are correct. [28] 


\subsection{Thermal equilibrium}

In Paper 1, 2 and 5, thermodynamic equilibrium modelling has been used to estimate the fraction of different species in the gas phase as well as fractions of different surface terminations. Thermodynamic equilibrium is achieved when the Gibbs free energy of the system is minimized. By knowing the entropy $(H)$ and enthalpy $(S)$ for the allowed species in the system, the concentrations of them in thermodynamic equilibrium is achieved when the Gibbs free energy $(\Delta G=\Delta H-T \Delta S$ ) for the whole system is minimized.

From thermodynamic equilibrium modelling it is not possible to retain what chemical reactions are taking place, only the end result products (and their concentrations).

\subsection{Kinetics}

Kinetics takes time into account. While thermal equilibrium can be considered as kinetics after infinite time, kinetics can show how concentrations of gas species evolve with time, which is not possible using equilibrium modelling.

The equations governing the rate at which the concentrations change are called rate equations. The rate equation is a differential equation relating the change of one species to the concentrations of other species. It is first when this differential equation is integrated that the time dependence for the concentration of a species is revealed.

A chemical reaction, with both forward and backward reactions may be written as

$$
a A+b B \rightleftharpoons c C+d D
$$

In this case the rate $r_{f}$ at with which $\mathrm{A}$ and $\mathrm{B}$ forms $\mathrm{C}$ and $\mathrm{D}$ is

$$
r_{f}=k_{f} \cdot[A]^{a}[B]^{b}
$$

where $[\mathrm{X}]$ being the concentration of $\mathrm{X}$ and $k_{f}$ being the rate constant for the forward reaction expressed as

$$
k_{f}=k_{A B} \cdot T^{n} \cdot e^{-E_{a} / R T}
$$

where $k_{A B}$ being a reaction constant, $T$ the temperature, $n$ the order of the temperature dependence, $E_{a}$ the activation energy of the reaction and $R$ the ideal gas constant. Both $k_{A B}$ and $n$ can be calculated using DFT, but can as well be determined experimentally. 
If there is a forward reaction there is also a backward reaction forming $\mathrm{A}$ and $\mathrm{B}$ from $\mathrm{C}$ and $\mathrm{D}$. This reaction occurs at the rate

$$
r_{b}=k_{b} \cdot[C]^{c}[D]^{d}
$$

where (6.4) is constructed in a similar manner as (6.2) and (6.3). The net rate $r$ at which $\mathrm{A}$ and $\mathrm{B}$ forms $\mathrm{C}$ and $\mathrm{D}$ is then

$$
r=r_{f}-r_{b}
$$

which can, by definition, also be expressed in terms of how the concentrations change with respect to time as

$$
r=-\frac{1}{a} \frac{d[A]}{d t}=-\frac{1}{b} \frac{d[B]}{d t}=\frac{1}{c} \frac{d[C]}{d t}=\frac{1}{d} \frac{d[D]}{d t}
$$

It is when $r=0$ equilibrium is reached since then the forward and backward reactions cancel.

$$
\begin{aligned}
r=0 & \Leftrightarrow r_{f}=r_{b} \Leftrightarrow \\
& \Leftrightarrow k_{f} \cdot[A]^{a}[B]^{b}=k_{b} \cdot[C]^{c}[D]^{d} \Leftrightarrow \\
& \Leftrightarrow \frac{k_{b}}{k_{f}}=\frac{[A]^{a}[B]^{b}}{[C]^{c}[D]^{d}}
\end{aligned}
$$




\section{CHAPTER 7}

CHARACTERIZATION

The characterization techniques related to this work are described below; optical microscopy, scanning electron microscopy, capacitance-voltage measurements and photoluminescence.

\subsection{Optical Microscopy}

For this work the most used characterization tool has been the optical microscope (sometimes abbreviated OM). It has been used to get a magnified image of a large area of sample from which surface morphology be determined. It can be used to measure distances on the surface in the range of micrometers and upwards, which could be used for rough estimates of thickness from triangular surface defects. The surface morphology around the onset of epitaxial growth (Paper 1) could be studied by the optical microscope.

The optical microscope uses optical lenses to enlarge objects. The object, which here has been the surface of a grown sample, can be studied in large magnification such that features in the $\mu \mathrm{m}$ range can be seen. The set-up used in this work was a differential interference contrast optical microscope using Normarski prisms. That is used to enhance height contrast in studied objects by letting polarized light passing through double refracting prisms. Doing so light polarized in different directions will exit the first Normarski prism slightly shifted, giving rise to slightly shifted light rays. That will create two slightly shifted images after finally reflect on the object, depending on polarization. The now slightly shifted 
images will, when superimposed, give rise to constructive or destructive interference due to phase shift from where the light has travelled different long paths for the different images. The front cover of this thesis shows an example of this. Due to the change in height there will be constructive or destructive interference of different wave length, resulting in the color shift around the feature.

\subsection{Scanning Electron Microscopy}

A scanning electron microscope (SEM) uses electrons instead of light to illuminate the sample. By focusing the electron beam, accelerated to a few $\mathrm{kV}$, on to a small spot of the sample and measure the intensity of e.g. backscattered (used in this work) or secondary electrons, an image is built up, pixel by pixel, as the electron beam is scanning the sample. Different intensities are achieved depending on features and composition of the material.

Different doping intensities will give rise to different conduction of electrons in the material. Higher conductivity will reduce the amount of backscattered electrons thereby resulting in a lower intensity. SiC substrates are normally high doped while unintentionally doped grown epitaxial are low doped. This gives a contrast difference between the substrate and the epitaxial layer and the thickness of the epitaxial layer can be measured.

There are a few problems associated with measuring thickness of SiC epitaxial layers using SEM. First, the sample has to be cut in half in order to get a cross section of the sample. By then irradiating the sample with accelerated electrons creates defects in sample such that other characterization methods should be done prior to SEM. Also, while scanning, charge is built up in the material due to the bad electrical conductivity of $\mathrm{SiC}$, such that the intensity of backscattered electrons is lower from an area previously scanned. This imprint allows never to zoom out or move the scanning area a fraction of the image, or otherwise is a darker imprint of the image. An example of this is shown in Figure 7.1.

\subsection{Capacitance-Voltage measurements}

One way to estimate doping concentration in a sample is by calculating it from capacitance-voltage (CV) measurements. The method does not measure the dopant concentration (i.e. the concentration of $\mathrm{N}$ and 


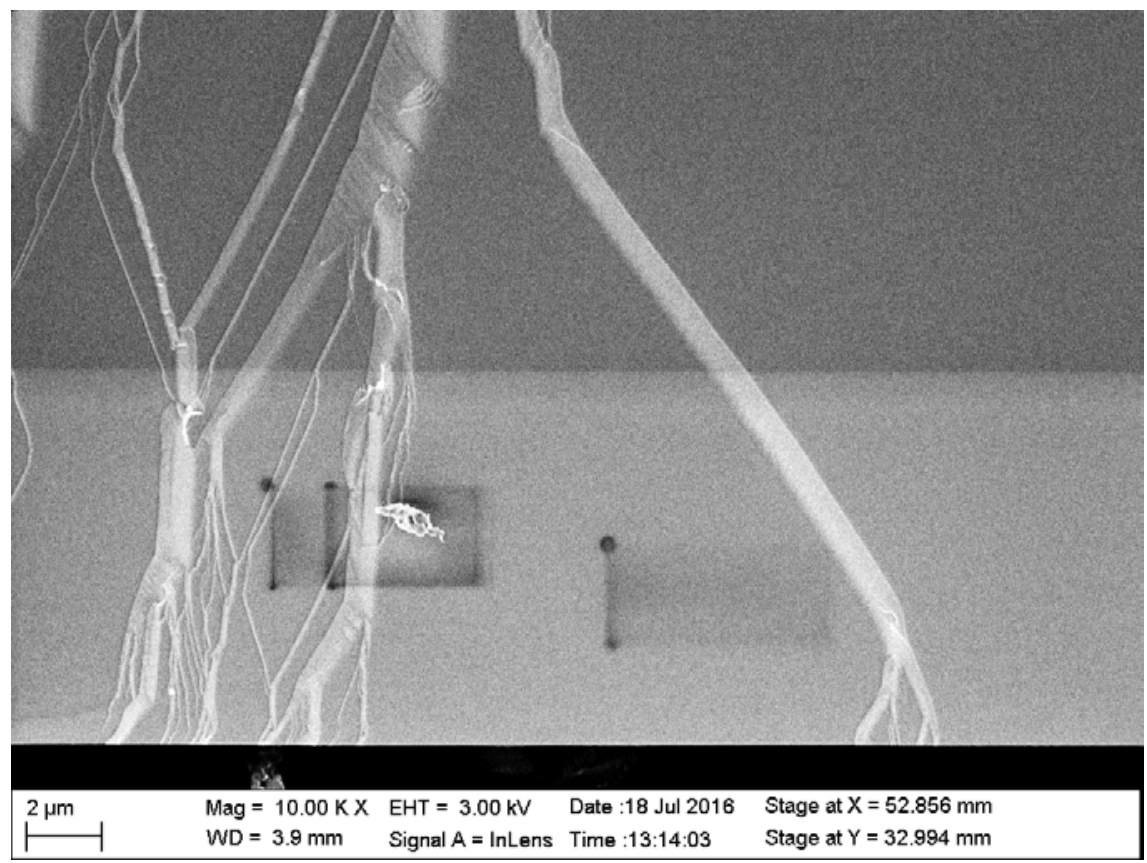

Figure 7.1: An example of a SiC cross section taken with SEM. Features due do a not clean cut are visible as well as imprints of previous zoomed in scans. Although a clear difference between the substrate and the epitaxial layer is seen.

concentration of $\mathrm{Al}$ ), but the net dopant concentration, which when measuring the net donor concentration is the difference in electrically active donors and electrically active acceptors. The capacitance-voltage meter measures how much the capacitance changes when different voltages are applied over the epitaxial layer. From this, the net dopant concentration can be calculated.

\subsection{Photoluminescence}

Photoluminescence (PL) is a characterization method where the carriers are excited and the radiative recombination of the carriers is studied. This excitation is usually done with photon energies above the band gap of the semiconductor $\left(E_{g}\right)$, normally by a laser. Above-band-gap excitation creates excitons, which is electron-hole pairs bound by their Coulomb interaction that is free to move in the crystal. The excitons may recombine 
as free excitons, or be captured at defects and impurities present in the crystal (bound excitons) and recombine there. In the latter case, the exciton energy is decreased by an amount equal to the binding energy of the exciton to the crystal imperfection, which is specific to the defect binding the exciton. In this way it is possible to study what defects and/or impurities are present inside the material, e.g. dopants and intrinsic defects.

The detection part of a photoluminescence setup usually consists of a monochromator containing a diffraction grating and a photosensitive detector (e.g. a photomultiplier or a CCD camera). The luminescence from the sample is collected with optical lenses directed to the grating, where the different wavelengths will diffract differently and produce a spectral image on the CCD. In a direct band gap semiconductor, the energy from the recombination of a free exciton is

$$
E=\hbar \omega=E_{g}-E_{F E}
$$

where $E_{F E}$ is the Coulomb energy binding the free exciton. However, in indirect semiconductors like $\mathrm{SiC}$, the momentum conservation prohibits direct recombination of the free exciton and leads to the appearance of the so-called phonon replicas in the spectrum. This is because a part of the exciton recombination energy is spent on the creation of momentum conserving phonon. Therefore, equation 7.1 becomes

$$
E=\hbar \omega=E_{g}-E_{F E}-E_{\text {phonon }},
$$

where $E_{\text {phonon }}$ is the energy of the phonon conserving the momentum. The free exciton can move in the lattice and bind to a dopant atom or a defect from where a bound exciton is created. If the bound exciton recombines, the recombination energy becomes

$$
E=\hbar \omega=E_{g}-E_{F E}-E_{B E},
$$

where $E_{B E}$ is the energy of binding of the exciton to the defect. This energy is defect-specific. This can then tell which impurities or defects are present in the material. Often the intensity of the PL lines is proportional to the defect concentration, and in some cases it is possible to determine, for instance, the nitrogen concentration in $\mathrm{SiC}$ by comparing the intensities of the free-exciton and nitrogen-bound exciton lines. [29]

To avoid broadening of the peaks due to that phonons are generated from heat in the material thereby broadening the needed energy of the phonon, measurements are usually performed at liquid helium temperatures $\sim 2 \mathrm{~K}$. This is called low temperature photoluminescence (LTPL). 


\section{CHAPTER 8}

FUTURE WORK

In this chapter I take the opportunity to briefly give you my thoughts on the fluoride based chemistry and what I would have thought would have been interesting to investigate further in this area. Personally I do not see that the fluoride chemistry will be able to compete with neither the chloride based chemistry nor the standard chemistry, if there is not a special reason for it, which goes beyond chemistry, e.g. isotopes. In my opinion the fluoride based chemistry has too many drawbacks - narrow process window, low and uneven deposition rates and dopant inclusions, as well as unpleasant exhaust gases, as demonstrated in Paper 1, 2 and 3.

The fluoride based chemistry has - as I see it - a role in the fundamental understanding of halogenated chemistries. Therefore, I see comparisons with the chlorinated and brominated chemistries as the most important future work in this area, as well as their comparison to the standard chemistry, a work which is now started (Paper 5). For further understanding of the fluoride based chemistry, growth using other precursors is my suggestion. In this work the $\mathrm{F}$ has been added via the $\mathrm{Si}$ precursor $\mathrm{SiF}_{4}$. It can also be added via the carbon precursor or by the addition of HF. The latter one gives a good possibility to compare it to standard and the halogenated chemistries since $\mathrm{SiH}_{4}+\mathrm{HX}, \mathrm{X}=\{\mathrm{Cl}, \mathrm{Br}\}$ are already investigated, as well as it gives a better opportunity to investigate the $\mathrm{F} / \mathrm{Si}$ than was done in Paper 2.

I also suggest that the surface chemistry is further investigated. To our current knowledge, a fluorinated chemistry causes fluorine terminated surface, but the mechanism behind creating the termination is still unclear. 
From a modelling point of view, further investigation of the kinetics, as well as using the results in a CFD model can give more insights to the understanding of the fluoride based chemistry. 
[1] J. A. Cooper and A. Agarwal, "SiC power-switching devices - The second electronics revolution?," Proceedings of the IEEE, vol. 90, no. 6, pp. 956-968, 2002.

[2] H. Matsunami, "Current SiC technology for power electronic devices beyond Si," Microelectronic Engineering, vol. 83, no. 1 SPEC. ISS., pp. 2-4, 2006.

[3] C. E. Weitzel, J. W. Palmour, C. H. Carter, K. Moore, K. J. Nordquist, S. Alien, C. Thero, and M. Bhatnagar, "Silicon carbide high-power devices," IEEE Transactions on Electron Devices, vol. 43, no. 10, pp. 1732-1741, 1996.

[4] E. A. Burgemeister, W. Von Muench, and E. Pettenpaul, "Thermal conductivity and electrical properties of $6 \mathrm{H}$ silicon carbide," Journal of Applied Physics, vol. 50, no. 9, pp. 5790-5794, 1979.

[5] C. Carter, Jr., V. Tsvetkov, R. Glass, D. Henshall, M. Brady, S. Müller, O. Kordina, K. Irvine, J. Edmond, H.-S. Kong, R. Singh, S. Allen, and J. Palmour, "Progress in SiC: from material growth to commercial device development," Materials Science and Engineering: B, vol. 6162, pp. 1-8, 1999.

[6] B. Thomas, W. Bartsch, R. a. Stein, R. Schörner, and D. Stephani, "Properties and Suitability of 4H-SiC Epitaxial Layers Grown at Different CVD Systems for High Voltage Applications," Materials Science Forum, vol. 457-460, pp. 181-184, 2004. 
[7] H. Pedersen, S. Leone, O. Kordina, A. Henry, S. I. Nishizawa, Y. Koshka, and E. Janzén, "Chloride-based CVD growth of silicon carbide for electronic applications," Chemical Reviews, vol. 112, no. 4, pp. 2434-2453, 2012.

[8] F. La Via, M. Camarda, and a. La Magna, "Mechanisms of growth and defect properties of epitaxial SiC," Applied Physics Reviews, vol. 1, p. 031301, sep 2014.

[9] T. Rana, M. V. S. Chandrashekhar, and T. S. Sudarshan, "Elimination of silicon gas phase nucleation using tetrafluorosilane (SiF4) precursor for high quality thick silicon carbide (SiC) homoepitaxy," Physica Status Solidi (A) Applications and Materials Science, vol. 209, no. 12, pp. 2455-2462, 2012.

[10] A. Balachandran, H. Song, T. Sudarshan, and M. Chandrashekhar, "4H-SiC homoepitaxy on nearly on-axis substrates using TFStowards high quality epitaxial growth," Journal of Crystal Growth, vol. 448, pp. 97-104, 2016.

[11] M. Yazdanfar, Ö. Danielsson, E. Kalered, P. Sukkaew, O. Kordina, D. Nilsson, I. G. Ivanov, L. Ojamäe, E. Janzén, and H. Pedersen, "Brominated chemistry for chemical vapor deposition of electronic grade SiC," Chemistry of Materials, vol. 27, no. 3, pp. 793-801, 2015.

[12] Bond Dissociation Energies, "Bond Dissociation Energies," in $C R C$ Handbook of Chemistry and Physics (Internet Version 2017) (W. M. Haynes, ed.), ch. 9, pp. 73-102, CRC Press/Taylor \& Francis, Boca Raton, FL, 97 ed., 2017.

[13] D. R. Lide, "Characteristic Bond Lengths in Free Molecules," in CRC Handbook of Chemistry and Physics (Internet Version 2017) (W. M. Haynes, ed.), ch. 9, p. 56, CRC Press/Taylor \& Francis, Boca Raton, FL, 97 ed., 2017.

[14] K. Shenai, R. S. Scott, and B. J. Baliga, "Optimum semiconductors for high-power electronics," IEEE Transactions on Electron Devices, vol. 36, no. 9, pp. 1811-1823, 1989.

[15] J. Fan and P. K. Chu, Silicon Carbide Nanostructures. Springer International Publishing Switzerland, 2014.

[16] H. Jagodzinski, "Eindimensionale Fehlordnung in Kristallen und ihr Einfluss auf die Röntgeninterferenzen. III. Vergleich 
der Berechnungen mit experimentellen Ergebnissen," Acta Crystallographica, vol. 2, no. 5, pp. 298-304, 1949.

[17] L. S. Ramsdell, "Studies on silicon carbide," American Mineralogist, vol. 32, pp. 64-82, 1947.

[18] D. J. Larkin, P. G. Neudeck, J. A. Powell, and L. G. Matus, "Sitecompetition epitaxy for superior silicon carbide electronics," Applied Physics Letters, vol. 65, pp. 1659-1661, 1994.

[19] Y. Tairov and V. Tsvetkov, "Investigation of growth processes of ingots of silicon carbide single crystals," Journal of Crystal Growth, vol. 43, no. 2, pp. 209-212, 1978.

[20] K. Abe, Y. Nagasaka, T. Kida, T. Yamakami, R. Hayashibe, and K. Kamimura, "Characterization of polycrystalline SiC films grown by HW-CVD using silicon tetrafluoride," Thin Solid Films, vol. 516, no. 5, pp. 637-640, 2008.

[21] O. Kordina, C. Hallin, R. C. Glass, A. Henry, and E. Janzén, "A novel hot-wall CVD reactor for SiC epitaxy," Inst. Phys. Conf. Ser., no. 137, pp. 41-44, 1993.

[22] J. Zhang, A. Ellison, Ö. Danielsson, M. K. Linnarsson, A. Henry, and E. Janzén, "Epitaxial growth of $4 \mathrm{H} \mathrm{SiC}$ in a vertical hot-wall CVD reactor: Comparison between up- and down-flow orientations," Journal of Crystal Growth, vol. 241, no. 4, pp. 421-430, 2002.

[23] H. Schlichting and K. Gersten, Boundary layer theory. SpringerVerlag Berlin Heidelberg, 8th ed., 2000.

[24] H. Matsunami and T. Kimoto, "Step-controlled epitaxial growth of SiC: High quality homoepitaxy," Materials Science and Engineering: R: Reports, vol. 20, no. 3, pp. 125-166, 1997.

[25] A. D. Becke, "Density-functional thermochemistry. III. The role of exact exchange," The Journal of Chemical Physics, vol. 98, no. 7, p. 5648, 1993.

[26] C. Lee, W. Yang, and R. G. Parr, "Development of the Colle-Salvetti correlation-energy formula into a functional of the electron density," Physical Review B, vol. 37, no. 2, pp. 785-789, 1988. 
[27] Y. Zhao and D. G. Truhlar, "The M06 suite of density functionals for main group thermochemistry, thermochemical kinetics, noncovalent interactions, excited states, and transition elements: Two new functionals and systematic testing of four M06-class functionals and 12 other function," Theoretical Chemistry Accounts, vol. 120, no. 1-3, pp. 215-241, 2008.

[28] Ö. Danielsson, P. Sukkaew, L. Ojamäe, O. Kordina, and E. Janzén, "Shortcomings of CVD modeling of SiC today," Theoretical Chemistry Accounts, vol. 132, p. 1398, 2013.

[29] I. Ivanov, C. Hallin, A. Henry, O. Kordina, and E. Janzén, "Nitrogen doping concentration as determined by photoluminescence in $4 \mathrm{H}-$ And 6H-SiC," Journal of Applied Physics, vol. 80, no. 6, pp. 35043508, 1996. 
In Paper 1 we investigate the Si chemistry in $\mathrm{F} \mathrm{SiC} \mathrm{CVD} \mathrm{by} \mathrm{using} \mathrm{SiF}_{4}$ as the Si precursor and source of $\mathrm{F}$. We find that the epitaxial growth is possible only if the effective $\mathrm{C} / \mathrm{Si}$ is low enough. By creating a system which upstream has a too high effective $\mathrm{C} / \mathrm{Si}$ ratio, which decreases along the susceptor, we could probe where the effective $\mathrm{C} / \mathrm{Si}$ is low enough for epitaxial growth. This position - which we named "the onset of epitaxial growth" - is used as a measurable to compare experiments to gas phase simulations using thermodynamic equilibrium. Doing such we were able to identify two $\mathrm{Si}$ species which could be growth species in the fluorinated chemistry. Then, using quantum chemical computations for surface reactions, we were able to conclude that $\mathrm{SiF}$ is the main growth species with SiHF as minor growth species.

In Paper 2 we continue to use the onset of epitaxial growth to identify the $\mathrm{C}$ growth species in $\mathrm{F} \mathrm{SiC} \mathrm{CVD} \mathrm{using} \mathrm{SiF}_{4}$. Here, we use three different $\mathrm{C}$ precursors and compare their positions for the onset of epitaxial growth. We also use kinetic gas phase modelling to compare the three different $\mathrm{C}$ precursors. We find that what $\mathrm{C}$ growth species are created $\left(\mathrm{C}_{2} \mathrm{H}_{2}\right.$ and $\left.\mathrm{CH}_{3}\right)$, and their concentration over time, is highly dependent on the choice of $\mathrm{C}$ precursor. We also show that the $\mathrm{C}$ precursor $\mathrm{CH}_{4}$ is a good choice of $\mathrm{C}$ precursor together with $\mathrm{SiF}_{4}$. From the kinetic simulations we also discover that atomic $\mathrm{Si}$ could temporarily be a $\mathrm{Si}$ growth species. As the $\mathrm{C}$ growth species are to attach to a $\mathrm{Si}$ monolayer, we here also investigate surface terminations on the $\mathrm{Si}$ face in a fluorinated environment by thermodynamic equilibrium. We find that the surface become highly $\mathrm{F}$ terminated. To investigate the role of $\mathrm{F}$ further we reduce 
the F/Si ratio by substituting $\mathrm{SiF}_{4}$ to $\mathrm{SiH}_{4}$ to different extent and conclude that the increase in growth rate when the amount of $\mathrm{F}$ is reduced could be attributed to the reduced amount of $\mathrm{F}$ in the system.

To investigate if F SiC CVD could be adopted for devices, we study dopant incorporation in Paper 3 in the F chemistry. For the doping, we show that the dopants behave like we are used to, although the presence of $\mathrm{F}$ influences the incorporation. We find large area doping homogeneity difficult - both for n-type using $\mathrm{N}_{2}$ and p-type using TMAl - most likely due to the higher amount of released F, discussed in Paper 2.

Despite the difficulties in doping uniformity, Paper 4 investigates if there are defects related to the F chemistry that makes the F chemistry inapplicable for growth of the active layer in devices. From photoluminescence and deep level transient spectroscopy no F-related defects were found.

Paper 5 puts the fluorinated chemistry in to a bigger context by comparing it to the other halogenated chemistries as well as the standard chemistry. Here it is shown that thermodynamic equilibrium calculations of the gas phase is good tool for investigating the gas phase composition by comparing them to the gas phase composition derived by kinetic. Here it is shown that the growth species in the other chemistries are similar to those in F system, namely $\mathrm{C}_{2} \mathrm{H}_{2}, \mathrm{CH}_{3}, \mathrm{Si}, \mathrm{SiH}_{\mathrm{x}}, \mathrm{SiX}$ and $\mathrm{SiHX}$, where $\mathrm{X}=\{\mathrm{Cl}, \mathrm{Br}($ and $\mathrm{F})\}$. 


\section{Papers}

The articles associated with this thesis have been removed for copyright reasons. For more details about these see:

http://urn.kb.se/resolve? urn:nbn:se:liu:diva-133832 